\title{
The relationship between Fusobacterium species and other flora in mixed infection
}

\author{
I. BROOK and R. I. WALKER
}

Naval Medical Research Institute, Bethesda, Maryland 20814 USA

\begin{abstract}
Summary. Mixed infections with three Fusobacterium species and seven other bacterial species were studied in a subcutaneous abscess model in mice. Fifteen Fusobacterium isolates (eight $F$. nucleatum, four $F$. necrophorum, and three $F$. varium) and one isolate each of Bacteroides fragilis, B. asaccharolyticus, Staphylococcus aureus, Group A $\beta$ haemolytic streptococcus, Escherichia coli, Klebsiella pneumoniae and Pseudomonas aeruginosa were studied. Electronmicrographs showed the presence of a thin mucopolysaccharide wall before and after inoculation into mice in 12 isolates which included all of 11 Fusobacterium isolates that induced subcutaneous abscesses. After co-inoculation of Fusobacterium isolates with other species and selective therapy with antimicrobial agents, $S$. aureus and $K$. pneumoniae were found to be of equal or greater importance in abscess induction than were Fusobacterium isolates, while Fusobacterium isolates were found to be more important than Group A streptococci and E. coli. Mutual enhancement of the numbers of organisms in mixed infections was observed with Fusobacterium spp. and $K$. pneumoniae, $P$. aeruginosa or Bacteriodes spp. Suppression of Fusobacterium spp. was noticed only when they were co-inoculated with Group A streptococci. The additive or synergistic capabilities of Fusobacterium species highlighted their potential pathogenicity in infection.
\end{abstract}

\section{Introduction}

Fusobacterium species are involved in various human infections where they are often isolated in mixed cultures with other anaerobic, facultative and aerobic bacteria (Brook, 1983). They are frequently involved in respiratory tract infections such as chronic sinusitis and otitis, peri-tonsillar abscesses, aspiration pneumonia and lung abscesses, and can also induce bacteraemia and intracranial infections. A few studies have investigated the synergistic potentials and importance of Fusobacterium spp. relative to other organisms in mixed infections (Altemeier, 1942; Conlon et al., 1977; Hill et al., 1974; Hite et al., 1949). In this study we produced subcutaneous (SC) abscesses in mice to evaluate the synergistic potentials between Fusobacterium species and other organisms with which they are commonly found in mixed infections. We determined the relative importance of organisms by selective inhibition with antibiotics and by quantitative cultures of abscess contents.

Received 3 Sep. 1984; revised version accepted 12 Apr. 1985.

\section{Materials and methods}

\section{Organisms}

All organisms were recent clinical isolates from patients admitted to the National Naval Medical Center, Bethesda, Maryland and were kept frozen in skimmed milk at $-70^{\circ} \mathrm{C}$. They included eight isolates of Fusobacterium nucleatum, four $F$. necrophorum, three $F$. varium and one isolate each of Bacteroides fragilis, B. asaccharolyticus, Staphylococcus aureus, Group A $\beta$ haemolytic streptococcus Escherichia coli, Klebsiella pneumoniae, and Pseudomonas aeruginosa. The isolates were identified by conventional methods (Lennette et al., 1980; Sutter et al., 1980).

\section{Capsular staining}

The presence of capsules was established by Hiss's stain before and after inoculation in mice, and was confirmed by electronmicroscopy after staining with ruthenium red (Kasper, 1976).

\section{Animals}

Male Swiss Albino mice, 20-25 g, were obtained from the Naval Medical Research Institute mouse colony (NMRI/NIH-CV). The mice were raised in conventional conditions. 


\section{Inoculum}

Frozen bacterial suspensions were thawed at room temperature, subcultured on to chocolate or Schaedleranaerobic blood agar (Difco Laboratoires, Detroit, MI), and incubated for $48 \mathrm{~h}$ at $37^{\circ} \mathrm{C}$ in an anaerobic glove box for the anaerobic bacteria, or in air with $\mathrm{CO}_{2} 5 \%$ for the aerobic bacteria. Twenty-four hours before injection, the bacterial isolates were inoculated on to Schaedler bloodagar plates with brain-heart infusion base (BHI, Difco). From these media, cotton swabs were used to pick colonies from the plates and transfer them to normal saline to give suspensions equivalent to a 10 MacFarland standard. Numbers of colony forming units (cfu) were determined by pour-plate counts in brain-heart infusion agar enriched with vitamin $\mathrm{K}_{1} 10 \mu \mathrm{g} / \mathrm{ml}$ and haemin $5 \mu \mathrm{g} /$ $\mathrm{ml}$.

\section{Abscess formation}

Mice were given subcutaneous (sc) injections in the right medial aspects of their thighs of $0.1 \mathrm{ml}$ of the appropriate bacterial suspensions in saline containing total counts of $10^{8} \mathrm{cfu}$ of each organism. The bacterial counts were estimated by nephelometry with MacFarland standard and the required density obtained by dilution. The doses were chosen to achieve minimal mortality, and maximal abscess formation (Brook et al., 1983). The size of the individual abscesses was determined during necropsy on the fifth day after inoculation. Although the volume of these abscesses could not be determined accurately, their sizes were compared by measuring two perpendicular diameters representing maximum length and width. Assuming that the abscess is an irregular prolate spheroid, the product of the length and width is proportional to the outer surface of the abscess. This product, expressed in $\mathrm{mm}^{2}$, was arbitrarily selected as the comparative measure. By this criterion, after 5 days without antibiotic therapy the abscesses caused by a single organism achieved an outer-surface size of 80-200 $\mathrm{mm}^{2}$, and abscesses caused by two organisms were 120$300 \mathrm{~mm}^{2}$.

\section{Examination of the abscesses}

Animals were killed by cervical dislocation and the abscess material was removed aseptically. The site and histology of the abscesses were confirmed, in two mice of each experimental group, by hematoxylin and eosin staining. The number of cfu of each isolate in an abscess was determined individually. The abscesses were homogenised inside a glove box in $1.0 \mathrm{ml}$ of sterile saline in a ground-glass tissue homogeniser. Ten-fold serial dilutions of the homogenates were made with sterile saline and $0.1 \mathrm{ml}$ of each dilution was spread in triplicate on enriched brain-heart infusion (BHI) and blood-agar plates. Colonies were counted after incubation for $48 \mathrm{~h}$ in aerobic or anaerobic conditions at $37^{\circ} \mathrm{C}$. Characteristic colonies of all isolates were picked and identified by Gram's stain and biochemical tests (Lennette et al., 1980;
Sutter et al., 1980). The results were analysed by Student's $t$ test.

\section{Antimicrobial agents and therapy}

Dosage of antimicrobial agents was based upon measurement of levels of drug in the serum of healthy mice after administration of selected doses. In most instances, this was approximately equal to the recommended doses for man $(\mathrm{mg} / \mathrm{kg})$.

The daily dosages of antimicrobial agents (administered in divided doses every $8 \mathrm{~h}$ ) were: penicillin $\mathrm{G}$ (Squibb and Sons, Princeton, NJ) $100 \mathrm{mg} / \mathrm{kg}$; metronidazole (Searle, Chicago, IL) $50 \mathrm{mg} / \mathrm{kg}$; gentamicin (Schering, Kenilworth, NJ) $7.5 \mathrm{mg} / \mathrm{kg}$. Treatment was initiated $2 \mathrm{~h}$ after inoculation and continued for 5 days. All agents were given by intramuscular injection.

\section{Sensitivity tests}

The minimal inhibitory concentrations (MIC) of each agent for all isolates were determined by the agar dilution technique (Thornsberry and Svenson, 1978).

\section{Measurement of antimicrobial agents in serum and abscess fluid}

Levels of antimicrobial agents in the sera and in the abscess contents were determined by the following methods: the agar diffusion assay (Lummis et al., 1978) for penicillin with Micrococcus luteus ATCC 934I (American Type Culture Collection, Rockville, MD), and for gentamicin with Bacillus subtilis ATCC 6051; high pressure chromatography (Wheeler et al., 1978) for metronidazole. Antibiotic levels were determined in serum and abscess fluid at 0.5 and $8 \mathrm{~h}$ after the last injection on day 5 of treatment. These samples were kept frozen at $-70 \mathrm{C}$ until they were assayed.

\section{Induction of abscesses}

The ability of an isolate to cause an abscess was determined by sc inoculation of $10^{8} \mathrm{cfu}$ of each isolate alone in $0.1 \mathrm{ml}$ of saline into groups of six mice. Abscesses were also induced by injection of mixtures containing $10^{*}$ cfu of each isolate in $0.2 \mathrm{ml}$ of saline into groups of six mice. The animals were observed for 28 days, and the abscess sizes were determined by external measurement without killing the animals. This experiment was repeated three times.

\section{Relative importance of isolates}

Abscesses were produced by inoculating a single isolate of Fusobacterium alone, a single isolate of the aerobic or facultative species alone, or a mixture of both into groups of 40 mice each (table 1). Each experiment was repeated three times. Two hours after inoculation, each group was divided into four sub-groups of 10 mice, receiving therapy by antimicrobial agents directed at (a) Fusobacterium 
Table I. Abscess surface size, 5 days after inoculation, in mice infected with Fusobacterium spp., alone or with other bacteria, and treated with various antibiotics

\begin{tabular}{|c|c|c|c|c|c|}
\hline \multirow{2}{*}{$\begin{array}{l}\text { Fusohacterium sp. and } \\
\text { species co-inoculated }\end{array}$} & \multicolumn{4}{|c|}{ Abscess size* after antimicrobial treatment against } & \multirow{2}{*}{$\begin{array}{l}\text { Species of greater } \\
\text { significancet }\end{array}$} \\
\hline & neither & Fusobacterium sp. & other species & both species & \\
\hline \multicolumn{6}{|l|}{ F. nucleatum $(F N)$} \\
\hline None & $124 \pm 20$ & $35 \pm 19$ & $132 \pm 37$ & $28 \pm 20$ & \\
\hline S. aureus (SA) & $245 \pm 67$ & $134 \pm 43$ & $12 \pm 8$ & $18 \pm 9$ & SA \\
\hline Group A streptococcus (GAS) & $232 \pm 55$ & $65 \pm 35$ & $285 \pm 52$ & $49 \pm 18$ & FN \\
\hline E. coli (EC) & $246 \pm 39$ & $18 \pm 10$ & $170 \pm 41$ & $24 \pm 21$ & FN \\
\hline K. pneumoniae (KP) & $208 \pm 48$ & $112 \pm 35$ & $26 \pm 21$ & $21 \pm 12$ & KP \\
\hline P. aeruginosa $(\mathrm{PA})$ & $216 \pm 72$ & $43 \pm 12$ & $27 \pm 19$ & $16 \pm 8$ & Equal \\
\hline \multicolumn{6}{|l|}{ F. necrophorum (F Ne) } \\
\hline None & $156 \pm 18$ & $40 \pm 16$ & $145 \pm 54$ & $25 \pm 16$ & \\
\hline S. aureus (SA) & $192 \pm 71$ & $215 \pm 34$ & $32 \pm 16$ & $46 \pm 19$ & SA \\
\hline Group A streptococcus (GAS) & $278 \pm 81$ & $30 \pm 24$ & $160 \pm 51$ & $38 \pm 21$ & $\mathrm{FNe}$ \\
\hline E. coli $(\mathrm{EC})$ & $306 \pm 64$ & $78 \pm 36$ & $205 \pm 37$ & $61 \pm 14$ & $\mathrm{FNe}$ \\
\hline K. pneumoniae (PA) & $224 \pm 75$ & $58 \pm 19$ & $44 \pm 27$ & $21 \pm 25$ & Equal \\
\hline P. aeruginosa & $180 \pm 50$ & $72 \pm 36$ & $58 \pm 30$ & $37 \pm 14$ & Equal \\
\hline \multicolumn{6}{|l|}{ F. carium $(F V)$} \\
\hline None & $192 \pm 39$ & $53 \pm 28$ & $205 \pm 42$ & $41 \pm 18$ & \\
\hline S. aureus & $262 \pm 43$ & $188 \pm 27$ & $39 \pm 18$ & $45 \pm 21$ & SA \\
\hline Group A streptococcus & $257 \pm 51$ & $54 \pm 24$ & $191 \pm 39$ & $59 \pm 37$ & FV \\
\hline E. coli & $285 \pm 64$ & $31 \pm 26$ & $129 \pm 59$ & $50 \pm 22$ & FV \\
\hline$K$. pneumoniae & $274 \pm 51$ & $154 \pm 40$ & $24 \pm 28$ & $19 \pm 25$ & $\mathrm{KP}$ \\
\hline$P$. aerignosa & $241 \pm 60$ & $163 \pm 44$ & $41 \pm 36$ & $47 \pm 15$ & $\mathrm{PA}$ \\
\hline
\end{tabular}

* Mean \pm standard deviation $\left(\mathrm{mm}^{2}\right)$.

† The organism of greater importance was that which caused abscesses that were significantly smaller $(p<0 \cdot 05)$. When no statistical difference was noted, the two organisms were considered to be equally important.

alone, (b) other bacteria alone, or (c) combined therapy against both Fusobacterium and the other bacteria; (d) control mice received no treatment. For the therapy of mixed infections with fusobacteria and aerobic or facultative Gram-negative aerobic bacilli, penicillin and gentamicin were used, penicillin therapy for the Fusobacterium spp. and gentamicin for the aerobic or facultative Gramnegative bacilli. For the therapy of mixed infections between fusobacteria and facultative Gram-positive cocci, gentamicin and metronidazole were used, gentamicin for the cocci and metronidazole for the fusobacteria. The effect of therapy on the combination of Fusobacterium spp. and Bacteroides spp. could not be tested because of the lack of antimicrobial agents that will selectively inhibit one of them only. Animals infected with two isolates were used to evaluate the relative importance of the isolates, and those infected with single agents were used to ascertain the in-vivo activity of antimicrobial agents.

The relative importance of the organisms causing the abscess was determined by comparing the abscess sizes in the animals treated with one or two antimicrobial agents with those in untreated control mice. For example, an abscess caused by a single organism, which was treated with an antimicrobial agent effective against that organism, was predicted to respond to therapy and be smaller than that in an untreated control animal. For an abscess caused by two organisms where therapy was directed against only one, the abscess was predicted to be smaller than in untreated control animals when the susceptible bacterial species was the greater contributor to the abscess. Thus, in mixed infections of organisms A and B, therapy directed only against bacterium $A$ could cause (a) no decrease in the abscess size (organism $B$ is more important in mixed infections that organism A), or (b) a larger decrease in abscess size than when organism $B$ was treated (A is more important than B). The statistical significance of the relative importance of the various micro-organisms was estimated by Student's $t$ test, comparing the sizes of abscesses caused by both organisms on the fifth day of therapy. The sizes of the abscesses in the group of mice treated with agents effective against the aerobic or facultative bacteria alone, were compared with the sizes of the abscesses in the group where the therapy was directed against the anaerobic bacteria alone. The organisms of greater significance were those with which the reduction in abscess size was significantly greater $(p<0.05)$ with the specific therapy. When no statistical difference was noted, the two organisms were considered to be equally significant. The subgroup infected with mixed flora and treated with two antimicrobial agents was included to observe any synergy 
between the drugs. Synergy was defined by statistically significant reduction $(p<0.05)$ in abscess size associated with addition of a second antimicrobial agent.

\section{Quantitative relationships between isolates}

Abscesses were induced by one encapsulated representative of each Fusobacterium species alone, or in combination with one isolate each of the other facultative and aerobic species. The abscesses were cultured and bacterial counts were performed on the fifth day after inoculation. Six mice were included in each experimental group and each experiment was repeated three times. The data were analysed by comparing the changes in each of the bacterial isolates present in the abscess with the numbers present in the control abscesses containing the single species (Student's $t$ test).

\section{Results}

\section{Encapsulation}

Electronmicrographs of thin sections of the Fusobacterium isolates before inoculation showed a thin dense capsule of mucopolysaccharide (fig. 1) in

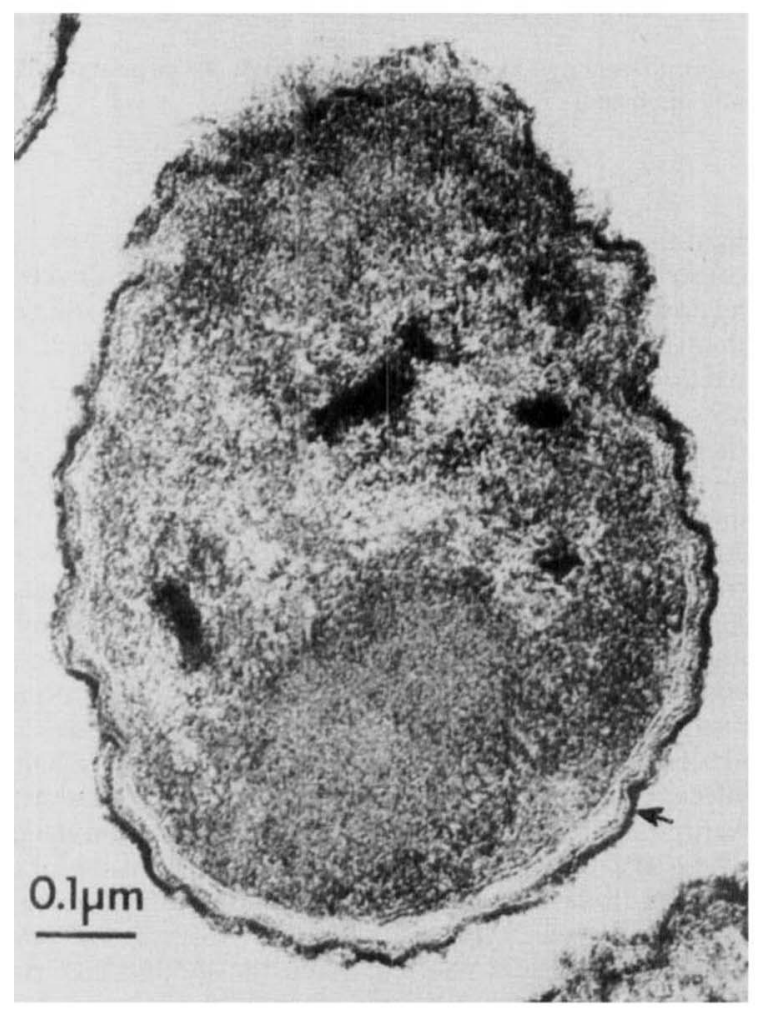

Fig. 1. Electronmicrograph of thin section of 48-h culture of $F$. nucleatum before animal passage; arrow indicates the thin capsule. $($ Bar $=0.5 \mathrm{~mm})(\times 78000)$. seven of the eight $F$. nucleatum isolates, two of the four $F$. necrophorum and all three $F$. varium. The capsule was seen in $>50 \%$ of the organisms seen among 1000 cells on a grid. After animal passage the density and size of the capsule layer were increased in all but two of the isolates used in the study (both $F$. nucleatum) (fig. 2) None of the unencapsulated strains acquired a capsule. Capsules were observed in smears stained by Hiss's method of all of the other isolates except $P$. aeruginosa before and after animal passages.

\section{Abscesses induced by single organisms}

Examination of abscesses caused by Fusobacterium spp. and other bacteria revealed the presence of a fibrous encapsulated collection of material which contained bacteria and polymorphonuclear leukocytes. Subcutaneous abscesses were found in at least $90 \%$ of the mice given 11 of the 15 Fusohacterium isolates. Isolates that induced abscesses included seven of the eight $F$. nucleatum, two of the four $F$. necrophorum and two of the three $F$. varium. Electronmicrographs of these isolates showed the

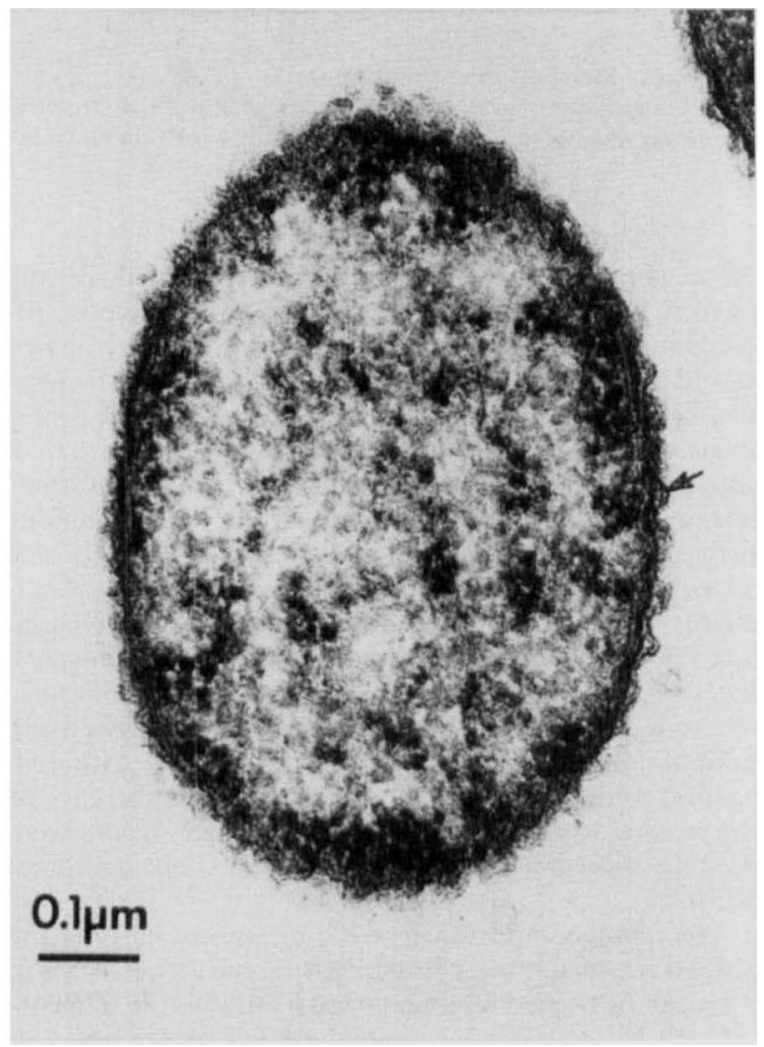

Fig. 2. Electronmicrograph of thin section of 48-h culture of $F$. nucleatum (same strain as fig. I) after animal passage; arrow indicates the thicker capsule $(\mathrm{Bar}=0.5 \mathrm{~mm})(\times 78000)$. 
presence of a mucopolysaccharide layer. Three of the four isolates that did not induce an abscess did not possess a capsular layer. Abscesses were formed within $24-48 \mathrm{~h}$ after sc inoculation with the fusobacteria. The abscesses reached a maximum diameter of $12-18 \mathrm{~mm}$ within 7 days, and most drained spontaneously or were absorbed within 14-21 days. No mice died after inoculation.

Abscesses caused by Bacteroides spp. were formed within $24-48 \mathrm{~h}$ in $85 \%$ of the mice, and the abscesses reached a diamater of $12-18 \mathrm{~mm}$ within 4-7 days. Up to $90 \%$ of the abscesses drained spontaneously within 9-12 days. No deaths occurred after inoculation.

$S$. aureus, Group A streptococcus, K. Pneumoniae, $P$. aeruginosa and $E$. coli isolates induced abscesses in at least $90 \%$ of mice, and the abscesses reached a diameter of $12-16 \mathrm{~mm}$ within 5-7 days. A mortality rate of about $10 \%$ was observed within the first $48 \mathrm{~h}$ after inoculation with all of these organisms except the Group-A streptococcus.

Abscesses induced by mixtures of Fusobacterium isolates and other organisms

After inoculation, abscesses developed in $82 \%$ of the animals given any of the combinations of one of the 15 Fusobacterium spp. and one of the other bacterial species within $48 \mathrm{~h}$. Abscesses reached a maximum diameter of about 22-26 mm within 5-7 days and, if untreated, drained spontaneously within 14-21 days. When animals died, mortality was similar to that found in animals with abscesses caused by the aerobic or facultative Gram-negative rods or $S$. aureus.

\section{In-vitro sensitivity to antibiotics}

The Fusobacterium isolates were uniformly susceptible to penicillin (MIC $\leq 0.5 \mu \mathrm{g} / \mathrm{ml}$ ) and metronidazole (MIC $\leq 0.1 \mu \mathrm{g} / \mathrm{ml}$ ) and resistant to gentamicin (MIC $>128 \mu \mathrm{g} / \mathrm{ml}$ ). The aerobic or facultative gram-negative rods and facultative cocci were resistant to penicillin (MIC $\geq 64 \mu \mathrm{g} / \mathrm{ml}$ ) and metronidazole (MIC $\geq 128 \mu \mathrm{g} / \mathrm{ml}$ ) and susceptible to gentamicin (MIC $<0.5 \mu \mathrm{g} / \mathrm{ml}$ ).

\section{Antibiotic levels in serum and abscess fluid}

Antibiotic levels were determined on the fifth day of therapy. The mean ( \pm SD) serum level of gentamicin determined in a group of 10 mice with abscesses caused by $F$. nucleatum was $6 \cdot 5 \pm 2 \cdot 2 \mu \mathrm{g} /$ $\mathrm{ml} 30 \mathrm{~min}$ after last dose, and $1.8 \pm 0.6 \mu \mathrm{g} / \mathrm{ml} 8 \mathrm{~h}$ later. The level in abscesses determined $30 \mathrm{~min}$ after the last dose was $5 \cdot 6 \pm 2 \cdot 2 \mu \mathrm{g} / \mathrm{ml}$. The mean levels of penicillin in serum were $27.5 \pm 8.2 \mu \mathrm{g} / \mathrm{ml}$ after 30 $\min , 6.8 \pm 2.4 \mu \mathrm{g} / \mathrm{ml}$ after $8 \mathrm{~h}$, and in abscesses $18.2 \pm 6 \cdot 2 \mu \mathrm{g} / \mathrm{ml}$ after $30 \mathrm{~min}$. The mean level of metronidazole in serum was $25.4 \pm 5 \cdot 3 \mu \mathrm{g} / \mathrm{ml}$ at 30 $\min , 10.8 \pm 3.2 \mu \mathrm{g} / \mathrm{ml}$ at $8 \mathrm{~h}$ and in abscesses $9.2 \pm 4.6 \mu \mathrm{g} / \mathrm{ml}$ at $30 \mathrm{~min}$. It is obvious that sufficient levels were achieved in both locations to inhibit susceptible strains.

Importance of Fusobacterium spp. relative to facultative and aerobic bacteria

The results obtained with combinations of Fusobacterium species and aerobic organisms and the assessment of species of greater significance are shown in table I. Abscesses caused by a single species always responded to antibiotic therapy directed at that species. These data were not included in table 1. After appropriate therapy, abscesses were smaller but did not disappear within 5 days. Abscesses inappropriately treated increased in size, as did untreated abscesses. No synergy between the antimicrobial agents was noticed. In mixtures of species, Fusobacterium spp. were less important than $S$. aureus, equally or less important than $K$. pneumoniae and $P$. aeruginosa, and more important than Group A streptococci and E. coli in abscess formation.

Quantitative relationships between Fusobacterium spp. and other bacteria in mixed infections

A summary of the changes that occurred in the numbers of Fusobacterium spp. and of the other species in an abscess produced by the mixture is presented in table II. The calculation was done by deducting the average log $10 \mathrm{cfu}$ of an organism when present mixed with another bacteria (see footnote, table II). An example of the calculation illustrates the relationship between $S$. aureus and $F$. nucleatum: the average $\log 10 \mathrm{cfu}$ in abscesses caused by single isolates were $S$. aureus $9 \cdot 2$ and $F$. nucleatum 7.5; the average log cfu in abscesses caused by two isolates were $S$. aureus 9.6 and $F$. nucleatum 10.9; Ratio of change $=9 \cdot 6-9 \cdot 2 /$ $10 \cdot 9-7 \cdot 5=0 \cdot 4 / 2 \cdot 4$.

Of the 21 combinations, numbers of fusobacteria were enhanced in 13 and inhibited in three (all with the Group A streptococcus). Numbers of other bacteria were enhanced in 12 of 21 combinations, and were never suppressed (table II). Numbers of Fusobacterium spp. were enhanced by $S$. aureus and $K$. pneumoniae. In most instances a concomitant increase occurred in both components of the mixed 
Table II. Quantitative relationship between strains in mixed infections

\begin{tabular}{|c|c|c|c|}
\hline \multirow[b]{2}{*}{ Species co-inoculated } & \multicolumn{3}{|c|}{$\begin{array}{l}\text { Ratio between change in numbers of } \\
\text { Fusobacterium spp. and other } \\
\text { bacteria in an abscess* }\end{array}$} \\
\hline & F. nucleatum & F. necrophorum & F. varium \\
\hline S. aureus & $0.4 / 2.4 \dagger$ & $0.8 / 2.8 \dagger$ & $1.2 / 3.4 \dagger$ \\
\hline Group A. streptococci & $0.6 /-2.6+$ & $1.0 /-3.5 t$ & $1 \cdot 2 /-1 \cdot 8 \dagger$ \\
\hline E. coli & $0.6 / 3.8 \dagger$ & $1 \cdot 2 / 1 \cdot 6$ & $2 \cdot 3+/ 2 \cdot 8 \dagger$ \\
\hline K. pneumoniae & $3 \cdot 4 \uparrow / 2 \cdot 2 \dagger$ & $3 \cdot 8+/ 2 \cdot 0+$ & $2.3+/ 1.9+$ \\
\hline$P$. aeruginosa & $2.6+/ 1.2$ & $2 \cdot 8 \dagger / 2 \cdot 4 \dagger$ & $1.4 / 2 \cdot 6 \dagger$ \\
\hline B. fragilis & $2 \cdot 6+/ 3 \cdot 2 \dagger$ & $3 \cdot 5+/ 2 \cdot 4 \dagger$ & $2 \cdot 6 \dagger / 1 \cdot 2$ \\
\hline B. asaccharolyticus & $3 \cdot 1+/ 2 \cdot 2 \dagger$ & $3 \cdot 4+/ 1 \cdot 2$ & $2 \cdot 0+/ 1 \cdot 3$ \\
\hline $\begin{array}{l}\text { Increase/decrease } \\
\text { of Fusobacterium }\end{array}$ & $5 / 1$ & $4 / 1$ & $4 / 1$ \\
\hline
\end{tabular}

\footnotetext{
* Change (vs. control) in average number of other organisms (log $10 \mathrm{cfu}) / \mathrm{change}$ (vs. control) in average number of Fusobacterium $\mathrm{sp}$. (control = the number of organisms in an abscess caused by the organism alone).

+ Significant differences between single and mixed infection $(\mathrm{p}<0.05)$.
}

infection. The combinations of $F$. nucleatum with other flora significantly increased the growth of the fusobacteria in five of the seven combinations and significantly decreased it in one (table II). Other bacteria were enhanced when mixed with $F$. nucleatum in four instances. Numbers of $F$. necrophorum in abscesses were increased in four combinations with other bacteria and decreased in one. Other bacteria were increased when combined with $F$. necrophorum in four instances. The numbers of $F$. varium in abscesses were increased in four combinations and decreased in one. Other bacteria were enhanced when combined with $F$. varium in four instances.

\section{Discussion}

Development of suitable animal models of infection are necessary to understand pathogenicity and synergy between species and to evaluate potential therapeutic agents for mixed infection. An important role of bacterial synergy in infection has been suggested by several investigators, and studies of synergistic activity have included the association of anaerobic bacteria with other species in various infections (Altemeier, 1942; Hite et al., 1949; Macdonald et al., 1956; Mergenhagen et al., 1958; Brook and Walker, 1983). Data from clinical specimens indicate that many infections in man are caused by mixed anaerobic or anaerobic and facultative species.

The clinical significance of the Bacteroidaceae, particularly $F$. necrophorum, as opportunistic pathogens in various diseases in animals is also well documented. Over the years a continuing effort has been made to understand the pathogenicity and importance of this organism in veterinary infections (Conlon et al., 1977).

Several animal models have been used to investigate the pathogenicity of Fusobacterium species. The only successful animal models developed with Fusobacterium species have been intra-hepatic abscesses in rabbits (Abe et al., 1976) and in mice (Hill et al., 1974) and lymphatic abscesses (Conlon et al., 1977). However, induction, monitoring and culturing such abscesses is complicated and cumbersome. The development, therefore, of subcutaneous abscesses in mice, as described in the present study, establishes a simple animal model that can be used for studies of pathogenicity (Brook and Walker, 1983) and for evaluation of the effect of antimicrobial therapy on single or mixed infections.

Several recent studies have demonstrated the pathogenicity of encapsulated anaerobes and their ability to induce abscesses alone. Onderdonk et al. (1977) correlated the virulence of $B$. fragilis strains with the presence of a capsule, and Simon et al. (1982) described decreased phagocytosis of the encapsulated $B$. fragilis. Capsular material from $B$. melaninogenicus also inhibits phagocytosis and phagocytic killing of other micro-organisms in an invitro system (Okuda and Takazoe, 1973).

We recently studied the relative importance of Bacteroides spp. and anaerobic Gram-positive cocci and their ability to cause an abscess in an animal model by virtue of capsule formation (Brook et al., 1983; Brook and Walker, 1983; Brook and Walker, 1984). With few exceptions, possession of a capsule 
generally made these organisms more important clinically than their aerobic counterparts. Although unencapsulated organisms did not induce abscesses, many of the strains which had only minimal numbers of encapsulated organisms $(<1 \%$ of the total population), survived in the abscess after inoculation with other aerobic and anaerobic bacteria and became heavily encapsulated. These heavily encapsulated strains were thereafter able to induce abscesses when injected alone.

As was found with other anaerobic bacteria, the ability of Fusobacterium strains to induce subcutaneous abscesses could be correlated with the presence of the thin mucopolysaccharide layer in the cell wall. The production of subcutaneous abscesses could be an indication of the organism's virulence, as has been noticed in other anaerobic strains (Kasper, 1976). In contrast to findings with other anaerobic species such as Bacteroides and Grampositive cocci (Brook and Walker, 1983; Brook et al., 1983; Brook and Walker, 1984), we did not observe minimally encapsulated fusobacterial organisms before animal inoculation. Review of a larger group of fusobacterial isolates may reveal such a phenomenon. However, we did observe an increase in the cell-wall density in fusobacterial cells after passage through mice.

The limitation of our animal model makes it difficult to ascertain the exact role of Fusobacterium spp. in mixed infections. We could determine which of the two isolates present in the mixed infection was the greater contributor to the infectious process only in a few isolates and this indirectly by using selective antimicrobial therapy. Furthermore, because many clinical infections involve more than two pathogens, our model may represent a simpli-

\section{REFERENCES}

Abe P M, Lennard E S, Holland J W 1976 Fusobacterium necrophorum infection in mice as a model for the study of liver abscess formation and induction of immunity. Infection and Immunity 13:1473-1478.

Altemeier W A 1942 The pathogenicity of the bacteria of appendicitis peritonitis: an experimental study. Surgery 11:374-384.

Brook I 1983 Anaerobic infections in childhood. G. K. Hall, Medical Publisher, Boston, MA.

Brook I, Gillmore J D, Coolbaugh J C, Walker R I 1983 Pathogenicity of encapsulated Bacteroides melaninogenicus group, Bacteroides oralis, and Bacteroides ruminicola subspecies brevis in abscesses in mice. Journal of Infection 7:218-226.

Brook I, Walker R I 1983 Infectivity of organisms recovered fied version of a true infection. The concomitant increase in the numbers of cfu of the two isolates present in the abscess could be due either to a mutual additive effect or is true synergy. However, the increase in abscess size and in numbers of cfu of both isolates suggests a mutual beneficial relationship.

Our study demonstrated the relationship of Fusobacterium species with other micro-organisms in mixed infections. The relationship between the bacteria in mixed infections varies with the different combinations. $S$. aureus and $K$. pneumoniae tend to be of greater or equal importance to the Fusobacterium species. In contrast, Fusobacterium species were of greater importance than the Group A streptococcus and $E$. coli. However, the co-inoculation without suppression by antimicrobial agents produced mutual enhancement of growth when Fusobacterium isolates were mixed with $K$. pneumoniae, $P$. aeruginosa or Bacteroides spp., and inhibition of growth when mixed with Group A streptococcus.

The additive or synergistic potential between Fusobacterium spp. and other bacteria, commonly cultivated in mixed cultures from infected sites, demonstrates the pathogenic potentials of fusobacteria. The synergy between these different bacterial strains may be due to protection from phagocytosis and intracellular killing (Simon et al., 1982), production of essential growth factors (Lev et al., 1971) or lowering of oxidation-reduction potential in host tissues (Mergenhagen et al., 1958).

The opinions and assertions contained herein are those of the authors and are not to be construed as official or reflecting the views of the Navy Department of the naval service at large. from polymicrobial abscesses. Infection and Immunity 42:986-989.

Brook I, Walker R I 1984 Pathogenicity of anaerobic Gram positive cocci. Infection and Immunity 45:320-324.

Conlon P J, Hepper K P, Teresa G W 1977 Evaluation of experimentally induced Fusobacterium necrophorum infections in mice. Infection and Immunity 15:510-517.

Hill G B, Osterhout S, Pratt P C 1974 Liver abscess production by non-spore-forming anaerobic bacteria in a mouse model. Infection and Immunity 9:599-603.

Hite K E, Locke M, Hesseltine H C 1949 Synergism in experimental infections with non-sporulating anaerobic bacteria. Journal of Infectious Diseases 84: 1-9.

Kasper D L 1976 The polysaccharide capsule of Bacteroides fragilis subspecies fragilis: Immunochemical and morphologic definition. Journal of Infectious Diseases 133:79-89.

Lennette E H, Balows A, Hausler W J, Truant J P 1980 Manual 
of clinical microbiology, 3rd edn. American Society for Microbiology, Washington, D.C.

Lev M, Keudell K C, Milford A F 1971 Succinate as a growth factor for Bacteroides melaninogenicus. Journal of Bacteriology 108:175-178.

Lummis W L, Davidson G M R, Wilson J W 1978 Clindamycin. In: Reeves D S et al. (eds) Laboratory methods in antimicrobial chemotherapy. Churchill Livingstone, Edinburgh, $p$ 216.

MacDonald J B, Sutton R M, Knoll M L, Madlener E M, Grainger R M 1956 The pathogenic components of an experimental fusospirochetal infection. Journal Infectious Diseases 98: 15-20.

Mergenhagen S E, Thonard J C, Scherp H W 1958 Studies on synergistic infections. I. Experimental infections with anaerobic streptococci. Journal of Infectious Diseases 103:33-44.

Okuda K, Takazoe I 1973 Antiphagocytic effects of the capsular structure of a pathogenic strain of Bacteroides melaninogenicus. Bulletin of the Tokyo Dental College 14:99-104.

Onderdonk A B, Kasper D L, Cisneros R L, Bartlett J G 1977
The capsular polysaccharide of Bacteroides fragilis as a virulence factor: Comparison of the pathogenic potential of encapsulated and unencapsulated strains. Journal of Infectious Diseases 136:82-89.

Simon G L, Klempner M S, Kasper D L, Gorbach S L 1982 Alterations in opsonophagocytic killing by neutrophils of Bacteroides fragilis associated with animal and laboratory passage: effect of capsular polysaccharide. Journal of Infectious Diseases 145:72-77.

Sutter V L, Citron D M, Finegold S M 1980 Wadsworth Anaerobic Bacteriology Manual, 3rd edn. C.V. Mosby, St Louis.

Thornsbury C, Svenson J M 1978 Antimicrobial susceptibility testing of anaerobes. Laboratory Medicine 9(10): 43-48.

Wheeler L A, DeMeo M, Halula M, George L, Heseltine P 1978 Use of high pressure liquid chromatography to determine plasma levels of metronidazole and metabolites after intravenous administration. Antimicrohial Agents and Chemotherapy 13:205-209. 